ARTICLE

\title{
Achieving stable Na metal cycling via polydopamine/multilayer graphene coating of a polypropylene separator
}

\author{
Jieqiong Qin 1,2,6, Haodong Shi13,4,6, Kai Huang 3,4,6, Pengfei Lu'1,3, Pengchao Wen ${ }^{1,3}$, Feifei Xing 1,3,4, \\ Bing Yang (i) ${ }^{3}$, Mao Ye (i) ${ }^{3 凶}$, Yan Yu (i) ${ }^{5 凶} \&$ Zhong-Shuai Wu (i) ${ }^{1,3 凶}$
}

Sodium metal batteries are considered one of the most promising low-cost high-energydensity electrochemical energy storage systems. However, the growth of unfavourable $\mathrm{Na}$ metal deposition and the limited cell cycle life hamper the application of this battery system at a large scale. Here, we propose the use of polypropylene separator coated with a composite material comprising polydopamine and multilayer graphene to tackle these issues. The oxygen- and nitrogen- containing moieties as well as the nano- and meso- porous network of the coating allow cycling of $\mathrm{Na}$ metal electrodes in symmetric cell configuration for over $2000 \mathrm{~h}$ with a stable $4 \mathrm{mV}$ overpotential at $1 \mathrm{mAcm}^{-2}$. When tested in full $\mathrm{Nall}$ $\mathrm{Na}_{3} \mathrm{~V}_{2}\left(\mathrm{PO}_{4}\right)_{3}$ coin cell, the coated separator enables the delivery of a stable capacity of about $100 \mathrm{mAh} \mathrm{g}^{-1}$ for 500 cycles (90\% capacity retention) at a specific current of $235 \mathrm{~mA} \mathrm{~g}^{-1}$ and satisfactory rate capability performances (i.e., $75 \mathrm{mAh} \mathrm{g}^{-1}$ at $3.5 \mathrm{~A} \mathrm{~g}^{-1}$ ).

\footnotetext{
${ }^{1}$ State Key Laboratory of Catalysis, Dalian Institute of Chemical Physics, Chinese Academy of Sciences, 457 Zhongshan Road, 116023 Dalian, China. ${ }^{2}$ College of Science, Henan Agricultural University, 63 Agricultural Road, 450002 Zhengzhou, China. ${ }^{3}$ Dalian National Laboratory for Clean Energy, Dalian Institute of Chemical Physics, Chinese Academy of Sciences, 457 Zhongshan Road, 116023 Dalian, China. ${ }^{4}$ University of Chinese Academy of Sciences, $19 \mathrm{~A}$ Yuquan Road, 100049 Shijingshan District, Beijing, China. ${ }^{5}$ Hefei National Laboratory for Physical Sciences at the Microscale, Department of Materials Science and Engineering, Key Laboratory of Materials for Energy Conversion, University of Science and Technology of China, 230026 Hefei, China. ${ }^{6}$ These authors

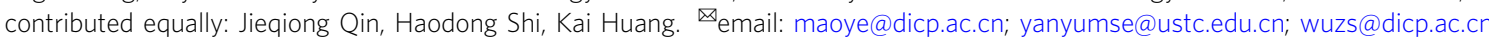


T he rapid growth of portable electronics, electric vehicle, autonomous aircraft, and smart grid has intensively stimulated the urgent requirements for low-cost, highenergy-density batteries ${ }^{1-4}$. Due to high theoretical capacity $\left(1166 \mathrm{mAh} \mathrm{g}^{-1}\right)$, low redox potential $(-2.714 \mathrm{~V}$ vs. standard hydrogen electrode), natural abundance and low price, metallic sodium $(\mathrm{Na})$ has been regarded as a highly competitive anode for next-generation rechargeable battery ${ }^{5-9}$. Unfortunately, its high reactive activity, large volume change, unstable solid electrolyte interphase (SEI), and uncontrollable dendritic growth bring about low Coulombic efficiency, limited cyclability, and even safety risk for high-energy-density $\mathrm{Na}$ metal batteries, such as $\mathrm{Na}-\mathrm{S}^{10}$ and $\mathrm{Na}-\mathrm{O}_{2}$ batteries ${ }^{11}$, substantially inhibiting their actual applications ${ }^{5,12-15}$. To overcome the issues, various strategies, including tailoring electrolyte formulation (e.g., highly concentrated electrolyte, fluoroethylene carbonate additive $)^{16,17}$, using solid-state electrolytes (gel polymer with boron nitride, $\left.\mathrm{Na}_{3} \mathrm{Zr}_{2} \mathrm{Si}_{2} \mathrm{PO}_{12}\right)^{18,19}$, creating artificial SEI (e.g., $\mathrm{Al}_{2} \mathrm{O}_{3}$, sodium benzenedithiolate, graphene $)^{20-22}$, and designing nanostructured $\mathrm{Na}$ anodes (e.g., Na@O-functionalized carbon nanotube networks, Na@porous Al, Na@carbonized wood) ${ }^{14,23,24}$, have been developed to suppress the growth of $\mathrm{Na}$ dendrites and realize stable and safe $\mathrm{Na}$ metal anodes. Nevertheless, these designs usually reveal single chemical or physical function for regulating $\mathrm{Na}$ dendrites, and faced high processing cost and limited scalability. Besides, constructing functional separators is considered as a more reliable and cost-effective way to realize uniform $\mathrm{Na}$ deposition from chemical molecule and physical structure levels ${ }^{25-27}$.

From the viewpoint of molecular level, polymer brushes with abundant polar functional groups (e.g., $\mathrm{C}=\mathrm{O},-\mathrm{OH},-\mathrm{COOH}$, and -NH-) can enhance the electrolyte wettability, provide robust SEI interface, and thus easily homogenize the alkali-metal ion distribution and nucleation ${ }^{21,28-32}$. In particular, structural twodimensional (s-2D) graphene-like polymer materials (e.g., poly(N-isopropylacrylamide), polyacrylamide grafted graphene oxide (GO), and polypyrrole-GO heterostructure) with sheet-like structure, high specific surface area (SSA), abundant surface chemistry and good mechanical flexibility, show tremendous advantage to regulate alkali-metal deposition and physically restrain dendrite puncture $22,28,29,33$. From the perspective of structure design, defective graphene and ordered mesoporous structure can serve as nanoporous buffer and ion channels to homogenize alkali-metal ion distribution and deposition ${ }^{33}$. Therefore, the reasonable construction of definable s-2D mesoporous functional polymer heterostructure for realizing stable, dendrite-free $\mathrm{Na}$ metal anodes from chemical molecule and physical structure levels is highly competitive yet remains elusive.
In this work, s-2D mesoporous polydopamine-graphene (mPG) heterostructures with definable pore diameter and sheet thickness are developed for stable, high-capacity $\mathrm{Na}$ metal anodes. Using free-standing s-2D substrate of $\mathrm{GO}$ and variable mesoporous template of $\mathrm{SiO}_{2}$ nanospheres, s-2D sandwich-like mPG heterostructures with adjustable pore sizes $(7,12,22 \mathrm{~nm})$, tailored sheet thickness $(14,20,28 \mathrm{~nm})$, and high SSA $\left(144,157,114 \mathrm{~m}^{2} \mathrm{~g}^{-1}\right)$ are successfully synthesized via GO based hard-template strategy. Owing to sodiophilic polydopamine surface, defective graphene layer, uniform mesoporous structure and high SSA, the s-2D mPG heterostructures are used as separator coating to endow Na metal anodes with Coulombic efficiency of $>99.5 \%$, cycling stability of $\sim 2000 \mathrm{~h}$ at $1 \mathrm{~mA} \mathrm{~cm}^{-2}$ with $1 \mathrm{mAh} \mathrm{cm}^{-2}$, and rate performance of $25 \mathrm{~mA} \mathrm{~cm}^{-2}$ with $25 \mathrm{mAh} \mathrm{cm}^{-2}$. As a consequence, coupled with carbon-coated $\mathrm{Na}_{3} \mathrm{~V}_{2}\left(\mathrm{PO}_{4}\right)_{3}$ (NVP@C) cathode, the mPGbased Na\|NVP@C full cells demonstrate stable cyclability with 90\% capacity retention over 500 cycles and rate capability showing a capacity of $75 \mathrm{mAh} \mathrm{g}^{-1}$ at $30 \mathrm{C}\left(1 \mathrm{C}=117.6 \mathrm{~mA} \mathrm{~g}^{-1}\right)$.

\section{Results}

Synthesis and physicochemical characterizations of s-2D mPG heterostructures. The synthesis process of s-2D mPG heterostructures is schematically shown in Fig. 1a. First, the GO nanosheets modified by polydiallyldimethylammonium chloride are employed as s-2D free-standing substrates. Then, monodispersed $\mathrm{SiO}_{2}$ nanospheres with negative charge serve as mesoporous templates to orderly assemble on the surface of $\mathrm{GO}$ substrates through electrostatic adsorption. Afterwards, homogeneous polydopamine (Supplementary Fig. 1) layer is patterned on the surface of as-prepared $\mathrm{SiO}_{2}$ - $\mathrm{GO}$ nanosheets to form $\mathrm{SiO}_{2}$ PGO nanosheets. Finally, s-2D mPG heterostructures with defined mesopore size and sheet thickness are generated after hydrothermal treatment (defined as $\mathrm{SiO}_{2}-\mathrm{PG}$ ) and $\mathrm{SiO}_{2}$ etching. It is worth noting that this template strategy can efficiently realize the strong coupling of sodiophilic polydopamine, defective reduced GO (rGO, Supplementary Fig. 2) and adjustable mesopores, which is highly conducive to construct multifunctional ion redistributors for dendrite-free $\mathrm{Na}$ metal anodes (Fig. 1b), as discussed below.

The microstructure and chemical composition of s-2D mPG heterostructures are presented in Fig. 2. Taking mPG with $12 \mathrm{~nm}$ mesopores (mPG-12) nanosheets as example, scanning electron microscopy (SEM) image displays flat and uniform s-2D morphology with lateral size ranging from 0.5 to $3 \mu \mathrm{m}$ (Fig. 2a). Transmission electron microscopy (TEM) and high-resolution TEM (HRTEM) images clearly indicate homogeneous mesoporous structure of mPG-12 nanosheets with uniformly ordered a

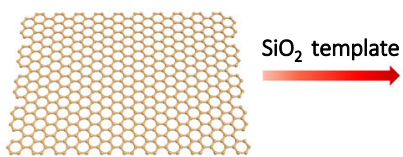

$\mathrm{GO}$

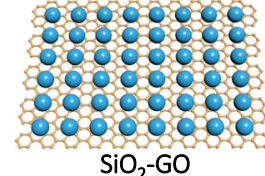

$\mathrm{SiO}_{2}-\mathrm{GO}$

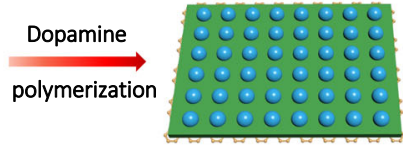

$\mathrm{SiO}_{2}-\mathrm{PGO}$
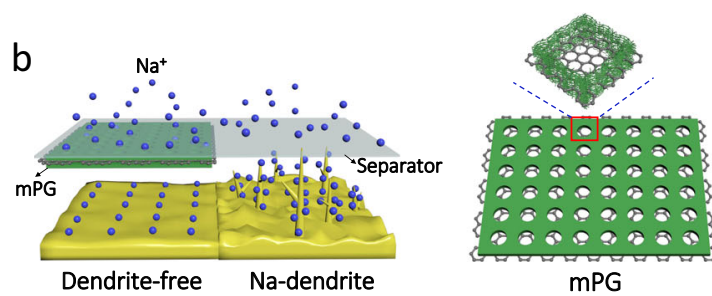

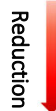

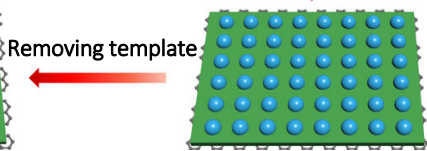

$\mathrm{SiO}_{2}-\mathrm{PG}$

Fig. 1 Scheme of s-2D mPG heterostructures for dendrite-free Na metal anode. a Schematic of the fabrication of s-2D mPG heterostructures, and b diagram of Na deposition behaviors with bare PP separator and mPG-coated PP separator. 

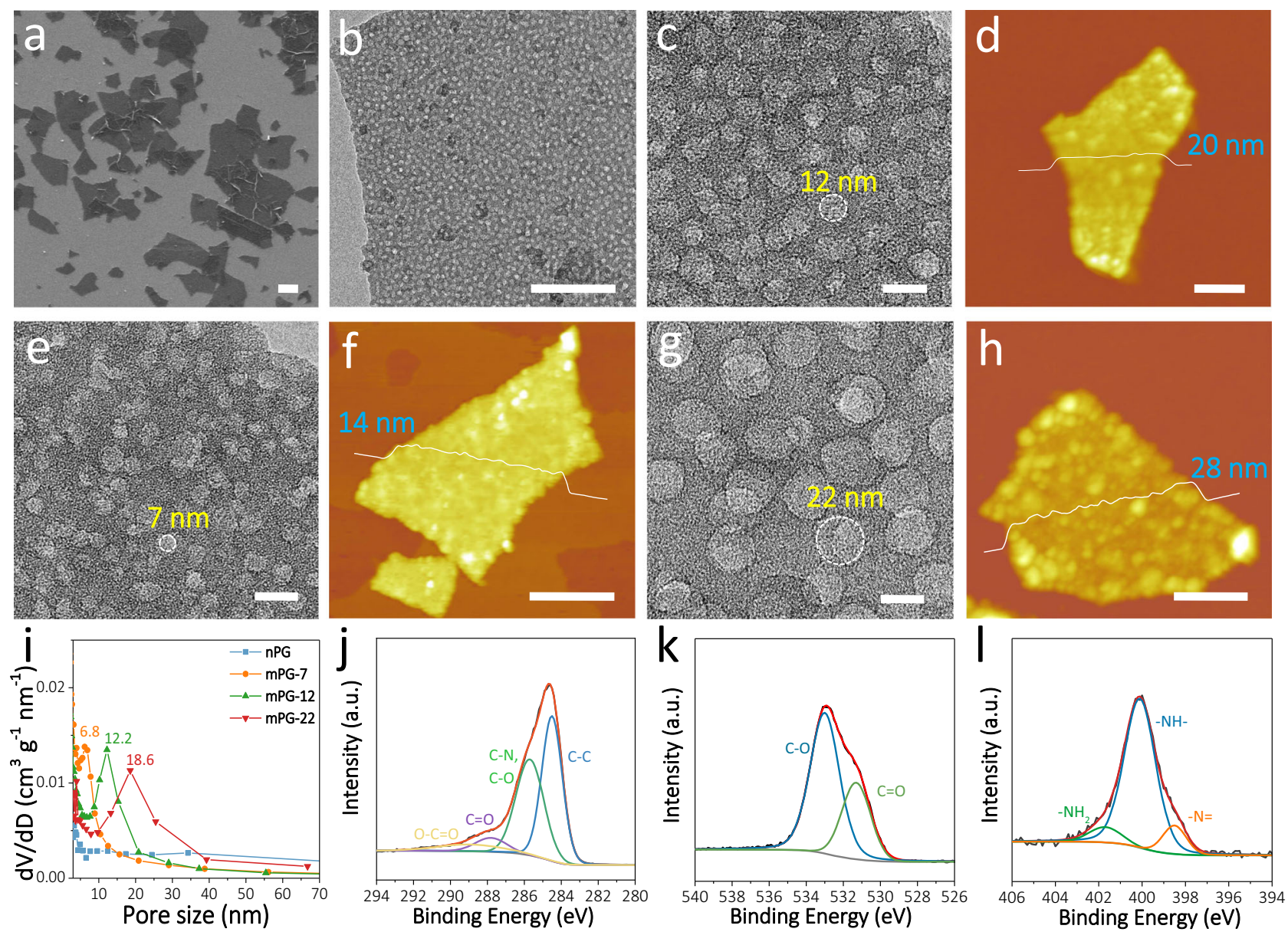

Fig. 2 Characterization of s-2D mPG heterostructures. a SEM image, $\mathbf{b}, \mathbf{c}$ TEM and HRTEM images, $\mathbf{d}$ AFM image and corresponding thickness analysis of mPG-12 nanosheets. e HRTEM image, $\mathbf{f}$ AFM image and corresponding thickness analysis of mPG-7 nanosheets. $\mathbf{g}$ HRTEM image, $\mathbf{h}$ AFM image and corresponding thickness analysis of mPG-22 nanosheets. $\mathbf{i}$ The pore size distribution curves of mPG-7, mPG-12, mPG-22, and nPG nanosheets. j-I Highresolution XPS (j) C $1 \mathrm{~s},(\mathbf{k}) O 1 \mathrm{~s}$, and (I) N 1s spectra of mPG-12 nanosheets. Scale bars: a $1 \mu \mathrm{m}, \mathbf{b} 200 \mathrm{~nm}, \mathbf{c}, \mathbf{e}, \mathbf{g} 20 \mathrm{~nm}$, and d, f, h $500 \mathrm{~nm}$.

mesopores of $\sim 12 \mathrm{~nm}$ (Fig. 2b, c). Atomic force microscopy (AFM) image reveals s-2D flat structure with a uniform thickness of $\sim 20 \mathrm{~nm}$ (Fig. 2d). More importantly, the patterning of mesoporous polydopamine with definable pore size and thickness on graphene surface can be precisely controlled, e.g., by changing the size of $\mathrm{SiO}_{2}$ template (Fig. 2e-h and Supplementary Fig. 3). Specially, mPG-7 nanosheets show uniform mesopores of $\sim 7 \mathrm{~nm}$ and an average thickness of $\sim 14 \mathrm{~nm}$, while mPG-22 nanosheets present ordered mesopores of $\sim 22 \mathrm{~nm}$ and sheet thickness of $\sim 28 \mathrm{~nm}$. Meanwhile, nonmesoporous polydopamine-graphene (nPG) nanosheets were also synthesized (Supplementary Fig. 4) to highlight the importance of structure-directing $\mathrm{SiO}_{2}$ templates. Moreover, $\mathrm{N}_{2}$ adsorption and desorption isotherms of mPG-7, mPG-12, mPG-22, and nPG nanosheets represent type IV curves with H2-type hysteresis loop (Supplementary Fig. 5). Notably, mPG-12 nanosheets display larger SSA of $157 \mathrm{~m}^{2} \mathrm{~g}^{-1}$ than mPG-7 $\left(144 \mathrm{~m}^{2} \mathrm{~g}^{-1}\right), \quad \mathrm{mPG}-22\left(114 \mathrm{~m}^{2} \mathrm{~g}^{-1}\right)$, and $\mathrm{nPG}\left(54 \mathrm{~m}^{2} \mathrm{~g}^{-1}\right)$ nanosheets (Supplementary Table 1). The dominated mesopore sizes of $6.8 \mathrm{~nm}$ for mPG-7, $12.2 \mathrm{~nm}$ for mPG-12, and $18.6 \mathrm{~nm}$ for mPG-22 nanosheets are well validated by the pore size distribution (Fig. 2i), nearly consistent with TEM observation. It is worth noting that the SSA generally changes with the variation of mesopore size and sheet thickness (Supplementary Figs. 5, 6). Fourier transform infrared spectroscopy (FT-IR) spectrum of mPG-12 reveals the existence of double peaks at 2930 and $2863 \mathrm{~cm}^{-1}$ featuring the indole structure, the characteristic vibration peak at $1712 \mathrm{~cm}^{-1}$ assigning to quinone $(\mathrm{C}=\mathrm{O})$ groups, and two distinct peaks at 1572 and $1462 \mathrm{~cm}^{-1}$ attributing to $\mathrm{C}=\mathrm{C}$ resonance vibration and $\mathrm{N}-\mathrm{H}$ bending vibration (Supplementary Fig. 7), demonstrative of the hybridization of polydopamine and graphene in mPG-12 $30,34,35$. Furthermore, X-ray photoelectron spectroscopy (XPS) of mPG-12 confirms three strong signals of $C$ $1 s, N 1 s$ and $O 1 s$ (Supplementary Fig. 8). The $C 1 s$ spectrum is fitted by four characteristic peaks of $284.5 \pm 0.1 \mathrm{eV}$ for $\mathrm{CH}_{\mathrm{x}}$ and $s p^{2}$-hybridized carbon, $285.7 \pm 0.2 \mathrm{eV}$ for $\mathrm{C}-\mathrm{O} / \mathrm{C}-\mathrm{N}, 287.8 \pm 0.2 \mathrm{eV}$ for $\mathrm{C}=\mathrm{O}$, and $288.9 \pm 0.2 \mathrm{eV}$ for $\mathrm{O}-\mathrm{C}=\mathrm{O}(\mathrm{Fig} .2 \mathrm{j})^{34,36,37}$. The $\mathrm{O} 1 \mathrm{~s}$ spectrum exhibits two peaks centered at $533.0 \pm 0.2 \mathrm{eV}$ for O-C and $531.3 \pm 0.1 \mathrm{eV}$ for $\mathrm{O}=\mathrm{C}$ (Fig. $2 \mathrm{k})^{34,36,37}$. Moreover, the $\mathrm{N} 1 \mathrm{~s}$ spectrum reveals three peaks at $401.7 \pm 0.1$ for $-\mathrm{NH}_{2}$, $400.0 \pm 0.1 \mathrm{eV}$ for $-\mathrm{NH}-$, and $398.5 \pm 0.1 \mathrm{eV}$ for $-\mathrm{N}=$ functional group, respectively (Fig. 2l) ) $^{34,36,37}$. It is evidenced that the mesoporous polydopamine layer is effectively grafted with graphene, and the abundant polar functional groups, e.g., $\mathrm{C}=\mathrm{O}$, $-\mathrm{OH}$, and $-\mathrm{NH}-$, are existed in s-2D mPG heterostructure.

Computational investigation on the Na-ion affinity and redistribution effect of $\mathbf{m P G}$. To examine the effects of polar functional groups and s-2D mesoporous structure on $\mathrm{Na}$ metal deposition, density functional theory (DFT) calculation and finite volume method (FVM) simulation were conducted. Figure 3a-c and Supplementary Fig. 9 display the binding energies and charge densities between $\mathrm{Na}$ atom and polydopamine, graphene, $\mathrm{PP}$ and $\mathrm{Cu}$. It can be seen that the interaction between $\mathrm{Na}$ and $\mathrm{Cu}$ 

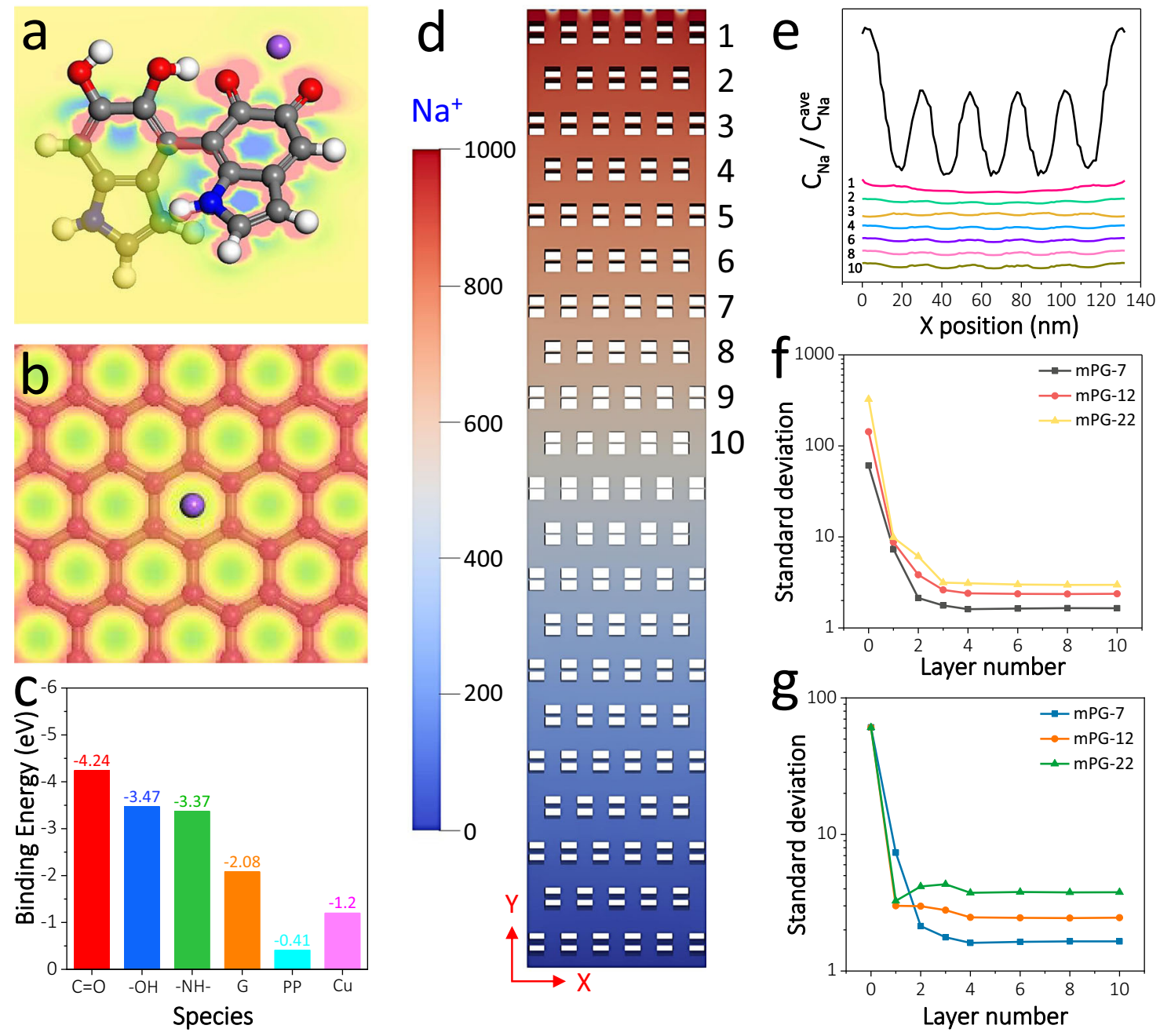

Fig. 3 Sodiophilic nature and Na-ion deposition behavior of S-2D mPG heterostructures by DFT calculation and FVM simulation. a The deformation charge density of polydopamine molecule with $\mathrm{Na}$. b The deformation charge density of graphene with Na. c Binding energies of Na with Cu, PP, graphene, and different functional groups in polydopamine. $\mathbf{d}$ Model diagram of $\mathrm{Na}$ ions through $\mathrm{mPG}$ layer (Inset: the color represents different concentration of $\mathrm{Na}$ ions). e The relative concentration of $\mathrm{Na}$ ions beneath different $\mathrm{mPG}$ layer with same amplitude and period of Na-ion distribution at the entrance. $\mathbf{f}, \mathbf{g}$ Standard deviation of Na-ion concentration beneath mPG-7, mPG-12, and mPG-22 layers with (f) same amplitude and ( $\mathbf{g}$ ) same fluctuation of Na-ion distribution at the entrance.

$(-1.20 \mathrm{eV})$ or PP $(-0.41 \mathrm{eV})$ is much weaker than that between $\mathrm{Na}$ and polydopamine, owing to abundant polar groups $(\mathrm{C}=\mathrm{O}$ of $-4.24 \mathrm{eV},-\mathrm{OH}$ of $-3.47 \mathrm{eV},-\mathrm{NH}-$ of $-3.37 \mathrm{eV})$ in polydopmine. Thus, the sodiophilic nature of $\mathrm{mPG}$ coupled polydopamine and graphene with a high binding energy of $-2.08 \mathrm{eV}$ can serve as active site to realize more uniform ion transport and $\mathrm{Na}$ deposition. Furthermore, the effect of mesopore size of s-2D mPG on Na-ion distribution is investigated by FVM simulation. As shown in Fig. 3d and Supplementary Fig. 10, the migration of $\mathrm{Na}$ ions driven by electric field and diffusion flow through 20 layers of $\mathrm{mPG}$ nanosheets is taken into account for the simulation. Although mPG heterostructures are fragile pieces in reality, $\mathrm{Na}$-ion flow driven by the vertical field between the two electrodes can be redistributed by s-2D mesoporous structure in $\mathrm{mPG}$ rather than perfect migration along the gaps between $\mathrm{mPG}$ nanosheets. As expected, with the shunting of mesopores in $\mathrm{mPG}$, the distribution of $\mathrm{Na}$ ions becomes increasingly uniform as the ions migrate along the $Y$-axis, and achieves the steady stability after four layers of mPG (Fig. 3e and Supplementary Fig. 11). The mPG-7 reveals the lowest standard deviation whether with same amplitude and period or same fluctuation and period of $\mathrm{Na}$-ion distribution at the entrance, implying the smaller mesopores are more beneficial to the redistribution and uniformity of $\mathrm{Na}$ ions (Fig. 3f, g). Further, the tunable SSA, mesopore size and thickness of $\mathrm{mPG}$ nanosheets can effectively regulate the $\mathrm{Na}$-ion diffusion across the separator and interface, and further influence the process of $\mathrm{Na}$ plating and SEI formation. As shown in the electrochemical impedance spectroscopy (EIS) plots (Supplementary Fig. 12), the mPG-12 based $\mathrm{Na} \| \mathrm{Cu}$ half cell presents lower interface resistance $(1.3 \Omega)$ and charge transfer resistance $(11.9 \Omega)$, as well as higher $\mathrm{Na}$-ion diffusion coefficient $\left(5.7 \times 10^{-12} \mathrm{~cm}^{2} \mathrm{~s}^{-1}\right)$, compared with those of mPG-7 (2.8 $\Omega$, $22.0 \Omega$ and $\left.2.7 \times 10^{-13} \mathrm{~cm}^{2} \mathrm{~s}^{-1}\right)$ and $\mathrm{mPG}-22(2.1 \Omega, 25.0 \Omega$ and $2.6 \times 10^{-12} \mathrm{~cm}^{2} \mathrm{~s}^{-1}$ ), possibly owing to larger SSA, appropriate mesopore size and thickness for efficient and uniform $\mathrm{Na}$ flux and deposition as well as stable SEI formation ${ }^{38-41}$. Taken the above into consideration, s-2D mPG heterostructures (especially mPG12) possess huge merits of serving as multifunctional separator coating to homogenize distribution of $\mathrm{Na}$ ions and prevent "tip effects" (alkali-metal ion easily deposited on the tips of the protuberances of $\mathrm{Cu}$ foils to produce dendrites owing to the increased electric and ionic fields) of $\mathrm{Na}$ deposition $33,39,42$. 

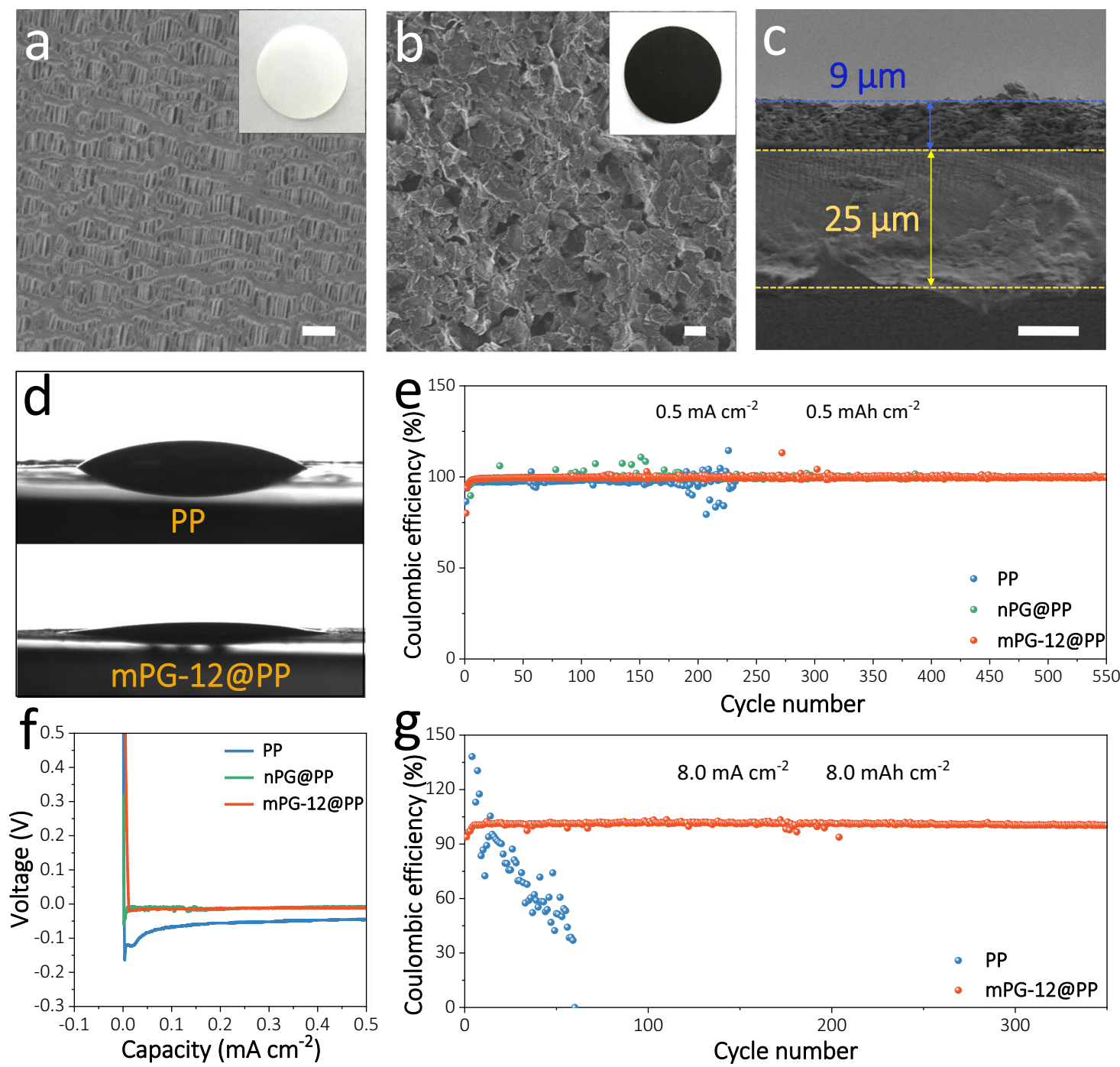

Fig. 4 Characterization and performance of mPG-12@PP separator for Na || Cu cells. a Top-view SEM image and photograph (inset) of bare PP separator. b Top-view SEM image and photograph (inset) of mPG-12@PP separator. c Cross-section SEM image of mPG-12@PP separator. d Contact angles of the electrolyte on bare PP (top) and mPG-12@PP (bottom) separators. e Coulombic efficiencies of Na || Cu cells with mPG-12@PP, nPG@PP and PP separators tested at $0.5 \mathrm{~mA} \mathrm{~cm}^{-2}, 0.5 \mathrm{mAh} \mathrm{cm}^{-2}$. $\mathbf{f}$ Voltage-capacity curves during Na nucleation with different separators. $\mathbf{g}$ Coulombic efficiencies of $\mathrm{Na} \| \mathrm{Cu}$ cells with mPG-12@PP and PP separators measured at $8.0 \mathrm{~mA} \mathrm{~cm}^{-2}, 8.0 \mathrm{mAh} \mathrm{cm}^{-2}$. Scale bars: a, b $1 \mu \mathrm{m}$, and $\mathbf{c} 10 \mu \mathrm{m}$.

Electrochemical characterizations in $\mathrm{Na} \| \mathrm{Cu}$ and $\mathrm{Na} \| \mathrm{Na}$ cell configurations. Considering the advantages of s-2D mPG heterostructures, we fabricated mPG-12 coated PP (mPG-12@PP) hybrid separators for $\mathrm{Na}$-ion storage in a nonaqueous cell using $\mathrm{Na}$ metal as negative electrode. Compared with bare PP separator with plenty of large pores $(\sim 500 \mathrm{~nm})$ and $25 \mu \mathrm{m}$ thickness, mPG-12@PP separators exhibit uniform, layer-stacked film (only $\sim 9 \mu \mathrm{m}$ thickness) of s-2D mPG-12 nanosheets on the surface of $\mathrm{PP}$, while retain good flexibility and well-defined pores (Fig. 4a-c and Supplementary Figs. 13, 14). Further, the contact angle of electrolyte on mPG-12@PP separator is $\sim 8^{\circ}$ (Fig. $4 \mathrm{~d}$ ), which is much lower than that on PP separator $\left(31^{\circ}\right)$, indicative of enhanced affinity of mPG-12@PP with electrolyte that is beneficial for Na-ion diffusion ${ }^{28,43}$.

To highlight the importance of mesopores in $\mathrm{mPG}-12$, nPGcoated PP (nPG@PP) separator was also assembled. The electrochemical performance of $\mathrm{Na} \| \mathrm{Cu}$ asymmetric cells with mPG-12@PP,nPG@PP, and PP separators was first evaluated to illustrate $\mathrm{Na}$ deposition behavior. At a current density of $0.5 \mathrm{~mA} \mathrm{~cm}^{-2}$ with a cycling capacity of $0.5 \mathrm{mAh} \mathrm{cm}^{-2}$, the $\mathrm{Na} \|$ $\mathrm{Cu}$ cells with mPG-12@PP separator exhibit stable plating/ stripping process for 550 cycles $(\sim 1100 \mathrm{~h})$ with a steady Coulombic efficiency of $\sim 99.8 \%$, which is better than that of nPG@PP (400 cycles with $\sim 99.5 \%$ Coulombic efficiency) and PP separators (200 cycles with $<90.0 \%$ Coulombic efficiency) (Fig. 4e and Supplementary Fig. 15). It can be well explained by the enlarged platingstripping curves (Fig. 4f), in which the $\mathrm{Na} \| \mathrm{Cu}$ cells with mPG12@PP separator show the lowest nucleation overpotential of only $20 \mathrm{mV}$ than those of $\mathrm{Na} \| \mathrm{Cu}$ cells with nPG@PP $(60 \mathrm{mV})$ and PP $(170 \mathrm{mV})$ separators. The reduced nucleation overpotential verifies the low interface resistance and enhanced $\mathrm{Na}$-ion transport kinetics through mPG-12@PP separator. Even at higher current density and areal capacity $\left(4.0 \mathrm{~mA} \mathrm{~cm}^{-2}\right.$ and $4.0 \mathrm{mAh} \mathrm{cm}^{-2}$; $8.0 \mathrm{~mA} \mathrm{~cm}^{-2}$ and $8.0 \mathrm{mAh} \mathrm{cm}^{-2}$ ), the Coulombic efficiency and cycling performance of $\mathrm{Na} \| \mathrm{Cu}$ cells with mPG-12@PP separator ( $\sim 99.9 \%$ for 450 cycles; $99.7 \%$ for 350 cycles) still outperform PP separator ( $\sim 78.5 \%$ for 90 cycles; $\sim 51.7 \%$ for 50 cycles) (Fig. $4 \mathrm{~g}$ and Supplementary Figs. 16, 17). These values are also higher than those of recently reported $\mathrm{Na}$ metal anodes stabilized by various strategies $^{14,44-53}$, demonstrating the advantage of mPG-12@PP separator for protecting $\mathrm{Na}$ metal anodes (Supplementary Table 2). To visually understand the impact of mPG-12@PP separator on 
$\mathrm{Na}$ plating/stripping process, the morphologies of $\mathrm{Na}$ metal anodes were traced by SEM (Supplementary Fig. 18). For the cell with bare $\mathrm{PP}$ separator, the anode exhibits $\mathrm{Na}$ dendrites with loosely mosslike structure at a $\mathrm{Na}$ loading of $1.0 \mathrm{mAh} \mathrm{cm}^{-2}$. In a sharp contrast, mPG-12@PP separator endows Na metal anode with a rather uniform and smooth surface without obvious dendrites, and this morphology becomes denser upon an increased $\mathrm{Na}$ loading of $2.0 \mathrm{mAh} \mathrm{cm}^{-2}$. The distinctive morphological transition of $\mathrm{Na}$ metal anodes with different separators demonstrates the key role of mPG-12 on efficient regulation of the Na-ion distribution and $\mathrm{Na}$ deposition. Meanwhile, SEM images of two sides of mPG-12@PP separator after 30 cycles were provided to visualize their changes. Prominently, the mPG-12 side reveals well-maintained flake-like and porous morphology, and the PP side keeps uniform, large pores on the surface, demonstrative of good structure stability of our mPG-12@PP separator (Supplementary Fig. 19).

Furthermore, symmetric Na \| Na cells were fabricated to assess the voltage hysteresis and cycling stability. Figure 5a exhibits the voltage-time curves of $\mathrm{Na} \| \mathrm{Na}$ cells with mPG-12@PP, nPG@PP, and bare PP separators at $1 \mathrm{~mA} \mathrm{~cm}^{-2}, 1 \mathrm{mAh} \mathrm{cm}^{-2}$. Notably, the cells with mPG-12@PP separator deliver virtually flat voltage plateaus over $2000 \mathrm{~h}$ with small overpotential $(4 \mathrm{mV})$, illustrating their good interfacial stability and cyclability. In a sharp contrast, the cells with nPG@PP display higher voltage hysteresis after $500 \mathrm{~h}(>14 \mathrm{mV})$, and the cells with bare PP separators appear micro-short circuiting after dozens of hours (inset of Fig. 5a and Supplementary Fig. 20). When increasing the areal capacity to $5 \mathrm{mAh} \mathrm{cm} \mathrm{cm}^{-2}$ or even $10 \mathrm{mAh} \mathrm{cm}^{-2}$, the cells with mPG-12@PP separator still show stable voltage plateaus over 1700 and $1400 \mathrm{~h}$, respectively (Supplementary Figs. 21, 22). Remarkably, such a long cycle life of $\mathrm{Na}$ anodes $(\sim 2000 \mathrm{~h}$ at $1 \mathrm{~mA} \mathrm{~cm}^{-2}$ and $1 \mathrm{mAh} \mathrm{cm}^{-2}, \sim 1700 \mathrm{~h}$ at $5 \mathrm{~mA} \mathrm{~cm}^{-2}$ and $5 \mathrm{mAh} \mathrm{cm}^{-2}$, and $\sim 1400 \mathrm{~h}$ at $10 \mathrm{~mA} \mathrm{~cm}^{-2}$ and $10 \mathrm{mAh} \mathrm{cm}^{-2}$ ) is better than those of other $\mathrm{Na}$ anodes stabilized by various methods under similar test conditions, such as 3D MXenemelamine foam $\left(720 \mathrm{~h} \text { at } 10 \mathrm{~mA} \mathrm{~cm}^{-2} \text { and } 10 \mathrm{mAh} \mathrm{cm}^{-2}\right)^{46}$, poly(vinylidene difluoride)-coated $\mathrm{Cu}$ current collector $(1200 \mathrm{~h}$ at $1 \mathrm{~mA} \mathrm{~cm}{ }^{-2}$ and $\left.1 \mathrm{mAh} \mathrm{cm}^{-2}\right)^{47}$, and $\mathrm{Na@rGO}$ anodes $(300 \mathrm{~h}$ at $5 \mathrm{~mA} \mathrm{~cm}^{-2}$ and $\left.5 \mathrm{mAh} \mathrm{cm}^{-2}\right)^{24}$, as shown as in Fig. $5 \mathrm{~b}$ and Supplementary Table $3^{21,44,48-50,54,55}$. What's more, the cells with mPG-12@PP separator reveal good rate capability under increasing current densities up to $25 \mathrm{~mA} \mathrm{~cm}^{-2}$ with $25 \mathrm{mAh} \mathrm{cm}^{-2}$ (overpotential $\approx 83 \mathrm{mV}$, Fig. $5 \mathrm{c}$ ), whereas the voltage-time curve of the cells with PP separator suffers from severe fluctuation (Supplementary Fig. 23). To the best of our knowledge, such a high rate performance $\left(25 \mathrm{~mA} \mathrm{~cm}^{-2}, 25 \mathrm{mAh} \mathrm{cm}^{-2}\right)$ greatly surpasses to those of the reported $\mathrm{Na}$ metal anodes stabilized by diversified strategies, such as 3D MXene-melamine foam $\left(20 \mathrm{~mA} \mathrm{~cm}^{-2}\right.$, $\left.20 \mathrm{mAh} \mathrm{cm}^{-2}\right)^{46}$, Na-Hg alloy $\left(8 \mathrm{~mA} \mathrm{~cm}^{-2}, 8 \mathrm{mAh} \mathrm{cm}^{-2}\right)^{56}$, coreshell C@Sb nanoparticles $\left(5 \mathrm{~mA} \mathrm{~cm}{ }^{-2}, 1 \mathrm{mAh} \mathrm{cm}{ }^{-2}\right)^{51}, \mathrm{Sb}_{2} \mathrm{MoO}_{6}$ microspheres $\quad\left(10 \mathrm{~mA} \mathrm{~cm}^{-2}, \quad 8 \mathrm{mAh} \mathrm{cm}^{-2}\right)^{52}$, oxygenfunctionalized carbon nanotube $\left(10 \mathrm{~mA} \mathrm{~cm}^{-2}, 2 \mathrm{mAh} \mathrm{cm}^{-2}\right)^{14}$, rGO aerogel $\left(5 \mathrm{~mA} \mathrm{~cm}^{-2}, \quad 5 \mathrm{mAh} \mathrm{cm}^{-2}\right)^{57}, \mathrm{Sn}^{2+}$ pillared $\mathrm{Ti}_{3} \mathrm{C}_{2}$ MXene $\left(8 \mathrm{~mA} \mathrm{~cm}^{-2}, 3 \mathrm{mAh} \mathrm{cm}^{-2}\right)^{53}$, porous $\mathrm{Cu}$ matrix $\left(3 \mathrm{~mA} \mathrm{~cm}^{-2}, 1 \mathrm{mAh} \mathrm{cm}^{-2}\right)^{54}$, and $3 \mathrm{D}$ carbon felt $\left(5 \mathrm{~mA} \mathrm{~cm}^{-2}\right.$, $\left.2 \mathrm{mAh} \mathrm{cm}^{-2}\right)^{58}$ (Fig. 5d and Supplementary Table 4). Further, from the EIS test, symmetric Na\| Na cells with mPG-12@PP separator exhibit smaller and more stable resistance than that with pure PP separator at different cycling stages (Supplementary Fig. 24). Consequently, the good cycling stability, high rate capability and small resistance variation suggest relatively rapid reaction kinetics and stable SEI layer of $\mathrm{Na}$ metal anodes with mPG-12@PP separator $28,33,59,60$.

Electrochemical characterizations in Na || NVP@C cell configuration. To highlight the applicability of mPG-coated

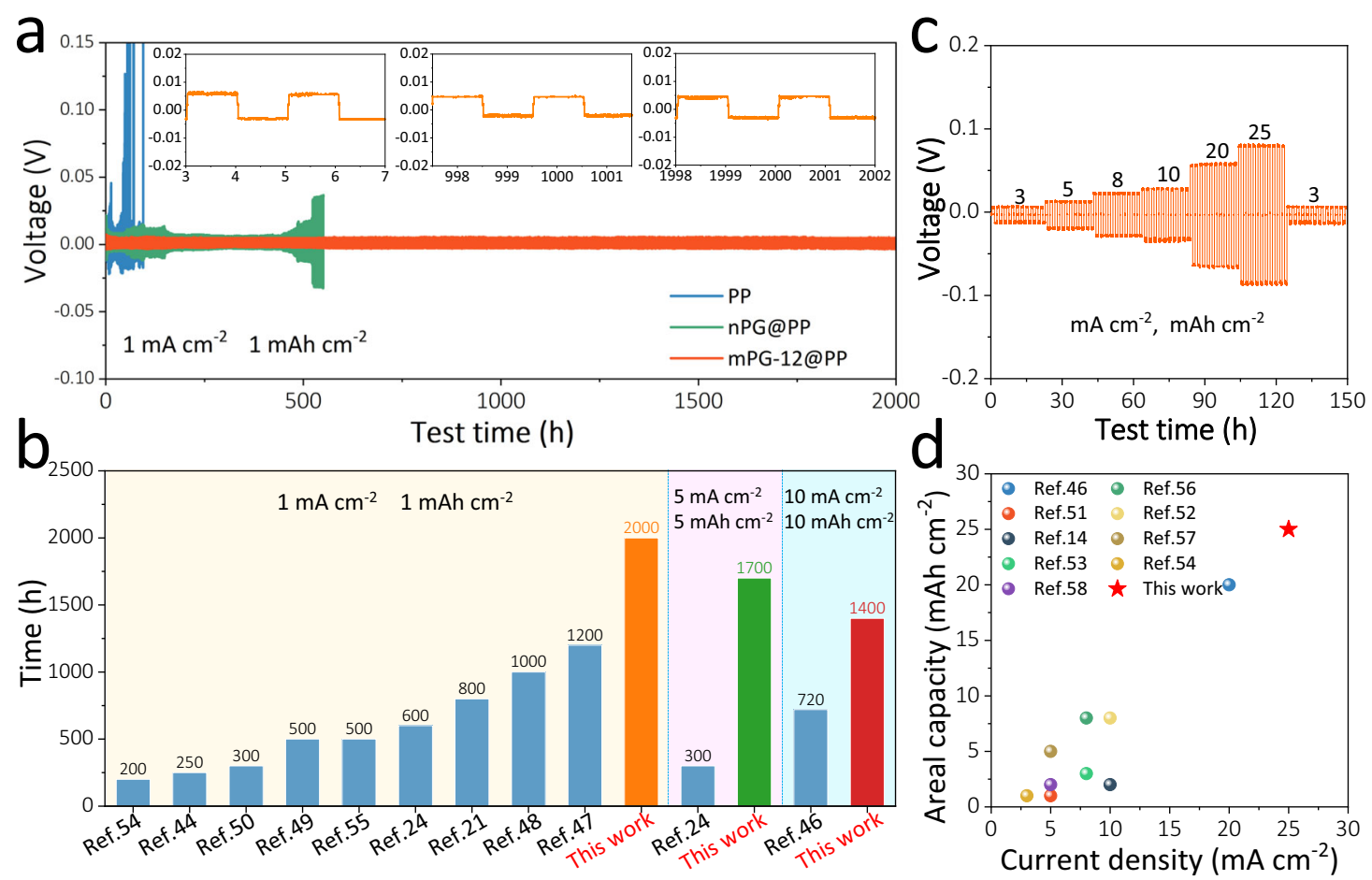

Fig. 5 Electrochemical characterization of mPG-12@PP separator for Na || Na symmetric cells. a Voltage-time profiles of Na || Na cells with mPG-12@PP, nPG@PP, and PP separators at $1 \mathrm{~mA} \mathrm{~cm}^{-2}, 1 \mathrm{mAh} \mathrm{cm}^{-2}$ (insets: magnified voltage profiles of Na || Na cell with mPG-12@PP at 5, 1000, and 2000 h, respectively). b Cycling stability comparison of $\mathrm{Na} \| \mathrm{Na}$ cells with mPG-12@PP separator and those of previously reported Na anodes stabilized by various methods at the same current densities and capacity. c Rate performance of Na || Na cells with mPG-12@PP separator obtained at different current densities and capacity, respectively.d Rate performance comparison of Na || Na cells with mPG-12@PP separator and other reported works recently. 

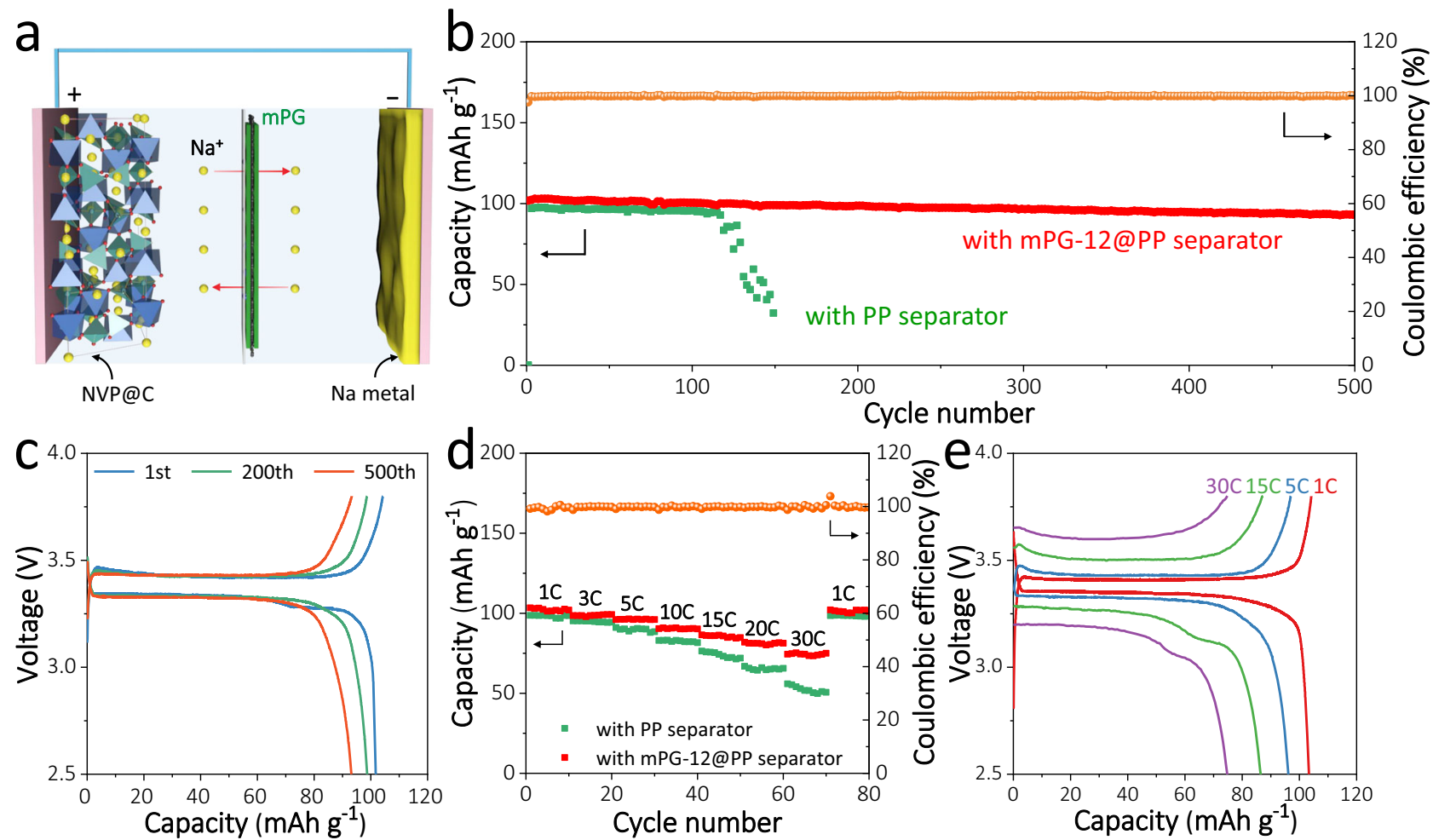

Fig. 6 Electrochemical performance of Na || NVP@C full cells with mPG-12@PP and PP separators. a Schematic illustration of Na || NVP@C full cell with mPG-coated separators. b Cycling stability obtained at a current density of 2C. c Galvanostatic charge-discharge profiles of Na || NVP@C full cells with mPG-12@PP separator at 2 C (1st, 200th, and 500th cycles).d Rate capability measured from 1 to 30 C. e Galvanostatic charge-discharge profiles of Na II NVP@C full cells with mPG-12@PP separator obtained at varying C-rate.

separator, we investigated a full cell comprising of an as-deposited

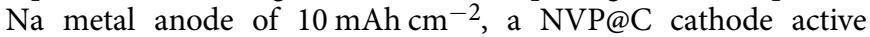
materials (Supplementary Fig. 25) and the MPG-coated separator (Fig. 6a) 5,61,62. Figure 6 b and Supplementary Fig. 26 exhibit the comparison of cycling stability of Na\|NVP@C full cells with mPG-12@PP and PP separators at 2C. Significantly, the Na\| NVP@C cell with mPG-12@PP separator demonstrates stable cycling performance with $90 \%$ retention of the initial capacity over 500 cycles, which surpasses that of Na || NVP@C cell with bare PP separator (decaying rapidly after 120 cycles), and other reported NVP@C based Na batteries (Fig. 6b, c) ${ }^{63,64}$. Moreover, the full cell with mPG-12@PP separator reveals better rate capability than that with PP separator (Fig. 6d and Supplementary Fig. 27). Specifically, the discharge capacities of the full cell with mPG-12@PP separator are 103, 96, 86 and $75 \mathrm{mAh} \mathrm{g}^{-1}$ at 1, 5, 15, and $30 \mathrm{C}$, higher than those of cell with PP separator $(99,91,76$, and $55 \mathrm{mAh} \mathrm{g}^{-1}$; Fig. 6e and Supplementary Fig. 28). It is noted that the observed kink at high rates may be derived from the limited available sites for sodium insertion at the end of the discharge (Supplementary Fig. 29) ${ }^{63,65,66}$, low sodium diffusion coefficient at the end of discharge status (Supplementary Fig. 30 $)^{41,67-69}$, and relatively low ionic conductivity of the electrolyte of $\mathrm{NaClO}_{4}$ in propylene carbonate ${ }^{65,70-74}$. In addition, even at a reduced capacity of $5 \mathrm{mAh} \mathrm{cm}^{-2}$ for the as-deposited $\mathrm{Na}$ anode $48,50,53,60,75,76$, our Na || NVP@C full cell with mPG12@PP separator still displays good cycling stability with $\sim 93 \%$ retention over 200 cycles, further indicating the effectiveness of mPG-12 for stable and high-energy-density $\mathrm{Na}$ metal batteries (Supplementary Fig. 31). On the other hand, when the mass loading of NVP@C is increased from 1 to $5 \mathrm{mg} \mathrm{cm}^{-2}$, the $\mathrm{Na} \|$ NVP@C full cells exhibit cycling stability of $>92 \%$ retention over 100 cycles at $0.5 \mathrm{C}$ (Supplementary Fig. 32). With the reduced deposition of $\mathrm{Na}$ anode $\left(5 \mathrm{mAh} \mathrm{cm}^{-2}\right)$ and relatively high loading of NVP@C (3.8 mg cm $\left.{ }^{-2}\right)$, our Na || NVP@C full cell with mPG12@PP separator also reveals better rate performance (99 $\mathrm{mAh} \mathrm{g}^{-1}$ at $1 \mathrm{C}$ and $72 \mathrm{mAh} \mathrm{g}^{-1}$ at $20 \mathrm{C}$ ) compared with $\mathrm{Na} \|$ NVP@C with PP separator (96 and $4 \mathrm{mAh} \mathrm{g}^{-1}$, Supplementary Fig. 33). Furthermore, mPG-12 coated separator also exhibits good performance for Cu || NVP@C cells (Supplementary Fig. 34). These results fully confirm that s-2D mPG-coated separator enable $\mathrm{Na}$ metal batteries with significantly enhanced Coulombic efficiency, cycling stability and rate performance.

\section{Discussion}

The good performance of $\mathrm{Na}$ metal anodes is attributed to the reasonable design of $\mathrm{s}-2 \mathrm{D}$ multifunctional $\mathrm{mPG}$ heterostructure synergistically coupled the sodiophilic polydopamine surface, $\mathrm{s}-2 \mathrm{D}$ defective graphene and definable mesoporous structure. First, the polydopamine layer features abundant polar groups, e.g., $\mathrm{C}=\mathrm{O},-\mathrm{OH}$, and $-\mathrm{NH}-$, endowing it with excellent electrolyte wettability and strong substrate adhesion to facilitate homogeneous $\mathrm{Na}$-ion transport and suppress the growth of $\mathrm{Na}$ dendrites at molecular level. Second, s-2D rGO with intrinsic defects, atomic thickness and excellent flexibility, offers a homogeneous Na-ion delivery by this nanoporous buffer layer ${ }^{25,33}$. Third, the exposed mesoporous structure not only increases the accessible contact area between active polydopamine and electrolyte, but also provides definable Na-ion pathways to regulate local current density and terminate the "tip effect". Consequently, s-2D mPG heterostructures as multifunctional separator coating substantially realize dendrite-free uniform $\mathrm{Na}$ deposition from chemical molecule to physical structure levels.

In summary, s-2D mPG heterostructures with definable pore size and sheet thickness have been demonstrated for stable and high-capacity $\mathrm{Na}$ anodes. Owing to the abundant sodiophilic 
groups, defective graphene and exposed mesoporous structure, $\mathrm{s}-2 \mathrm{D} \mathrm{mPG}$ heterostructures endow uniform $\mathrm{Na}$-ion transport and dendrite-free $\mathrm{Na}$ deposition, as confirmed by both theoretical and experimental analysis. Notably, the Na metal anodes with mPG12@PP separator exhibit high Coulombic efficiency ( $>99.5 \%)$, good cycling stability $(2000 \mathrm{~h})$, and landmark rate performance $\left(25 \mathrm{~mA} \mathrm{~cm}^{-2}\right.$ and $\left.25 \mathrm{mAh} \mathrm{cm}^{-2}\right)$. Further, s-2D mPG-coated separator realizes Na || NVP@C cells and Cu || NVP@C cells with improved electrochemical performance. Therefore, this strategy paves a new avenue for the design of s-2D mesoporous polymer materials towards next-generation safe, rechargeable sodium metal batteries.

\section{Methods}

Synthesis of GO. According to modified Hummers method $77,78,5 \mathrm{~g}$ of graphite powder was added to concentrated $\mathrm{H}_{2} \mathrm{SO}_{4}$ of $130 \mathrm{~mL}$ and stirred for $20 \mathrm{~min}$ in icewater bath. Then, $2.5 \mathrm{~g}$ of $\mathrm{NaNO}_{3}$ was added with continue stirring for $2 \mathrm{~h}$. Afterwards, $15 \mathrm{~g}$ of $\mathrm{KMnO}_{4}$ was slowly added to reaction solution within $1 \mathrm{~h}$, and continued to stir for $2 \mathrm{~h}$ under ice-water bath. Further, the reaction solution was transferred to water bath of $35^{\circ} \mathrm{C}$. After reacting $1 \mathrm{~h}, 230 \mathrm{ml}$ of high-purity water was slowly added with the temperature of $<40^{\circ} \mathrm{C}$. Then, the reaction temperature was improved to $98^{\circ} \mathrm{C}$ and kept for $30 \mathrm{~min}$. When the reaction was finished, $400 \mathrm{ml}$ of high-purity water and $10 \mathrm{ml}$ of $\mathrm{H}_{2} \mathrm{O}_{2}$ were gradually added to stir for $1 \mathrm{~h}$. Finally, brown GO suspension $\left(\sim 7 \mathrm{mg} \mathrm{mL}^{-1}\right)$ was obtained by repeated centrifugation, dialysis, and ultrasonic dispersion.

Synthesis of s-2D mPG heterostructures. Typically, $18 \mathrm{mg}$ of GO was added into the polydiallyldimethylammonium chloride solution $(0.2 \mathrm{wt} \%)$ of $75 \mathrm{~mL}$ and stirred for $24 \mathrm{~h}$. Then, $100 \mathrm{~mL}$ monodisperse $\mathrm{SiO}_{2}$ nanospheres solution (1.5 wt $\%$ ) was slowly added into the mixture under stirring for $15 \mathrm{~h}$. After centrifugation to remove excess $\mathrm{SiO}_{2}$ nanospheres, the $\mathrm{SiO}_{2}-\mathrm{GO}$ nanosheets were collected. Afterwards, as-obtained $\mathrm{SiO}_{2}$-GO were dispersed in $150 \mathrm{~mL}$ water to pattern polydopmine layers by adding a certain amount of dopamine hydrochloride and $180 \mathrm{mg}$ of Tris-base. Finally, s-2D mPG heterostructures were obtained after hydrothermal treatment at $180^{\circ} \mathrm{C}$ for $12 \mathrm{~h}$ and etching $\mathrm{SiO}_{2}$ by $\mathrm{HF}$ solution. According to the sizes of $\mathrm{SiO}_{2}$ template with 7,12 , and $22 \mathrm{~nm}$, and the addition amounts of dopamine hydrochloride for 450,600 , and $900 \mathrm{mg}$, the as-synthesized mPG heterostructures were defined as $\mathrm{mPG}-7$, mPG-12, and $\mathrm{mPG}-22$ nanosheets, respectively. For comparison, the nPG nanosheets without mesopores were also synthesized without using $\mathrm{SiO}_{2}$ template, while other steps kept same as mPG-12 nanosheets.

Fabrication of functional composite separators. The mPG-12 and polyvinylidene difluoride (PVDF) binder with a mass ratio of 90:10 were mixed in $\mathrm{N}$ methyl-2-pyrrolidinone (NMP, $\sim 0.5 \mathrm{~mL}$ ) with grinding $\sim 30 \mathrm{~min}$ to form a viscous solution. Then, the as-prepared suspension was blade-coated onto one side of a commercial PP separator (Celgard 2400, 25 $\mu \mathrm{m}$ ) with a blade of $100 \mu \mathrm{m}$. After vacuum drying at $80^{\circ} \mathrm{C}$ overnight and punching into disks with a diameter of $19 \mathrm{~mm}$, the mPG-12@PP separator $(\sim 34 \mu \mathrm{m})$ was successfully obtained.

Characterization. The morphology and composition of materials, separators, and electrodes were recorded by SEM (JSM-7800F), TEM (JEM-2100), AFM (Veeco nanoscope multimode II-D), $\mathrm{N}_{2}$ adsorption and desorption isotherm (Quadrasorb SI), FT-IR (Hyperion 3000), carbon/sulfur elemental analyzer (HORIBA EMIA8100), XPS (ESCALAB 250Xi) equipped with monochromatic Al Ka source of $1486.6 \mathrm{eV}$, and contact angle meter (DSA100).

Electrochemical measurement. All the cells were assembled with CR2016 coin cells in an Ar-filled glovebox $\left(\mathrm{H}_{2} \mathrm{O}<1 \mathrm{ppm} ; \mathrm{O}_{2}<1 \mathrm{ppm}\right)$, and all the electrochemical measurements were conducted using a LAND CT2001A battery system on a lab bench with the environmental temperature of $\sim 26^{\circ} \mathrm{C}$. The electrolyte used for $\mathrm{Na}$ deposition was $1 \mathrm{M} \mathrm{NaPF}_{6}$ in diglyme $(\sim 40 \mu \mathrm{L})$, while the electrolyte applied to Na || NVP@C full cells was $1 \mathrm{M} \mathrm{NaClO}_{4}$ in propylene carbonate with $5 \mathrm{wt} \%$ fluoroethylene carbonates $(\sim 100 \mu \mathrm{L})$. The water content of these nonaqueous electrolytes is $<20 \mathrm{ppm}$. The $\mathrm{Na} \| \mathrm{Cu}$ cells were assembled with $\mathrm{Cu}$ foil as the working electrode, $\mathrm{Na}$ disc (thickness: $500 \mu \mathrm{m}$; purity: $99.9 \%$ ) as the counter/ reference electrode, and the coated side of functional separators toward $\mathrm{Cu}$ foil. The $\mathrm{Na} \| \mathrm{Cu}$ cells were precycled five cycles from 0.1 to $3.0 \mathrm{~V}$ to stabilize the SEI, and then evaluated the Coulombic efficiency of $\mathrm{Na}$ plating/stripping. At the start of SoC ( $\mathrm{SoC}=0$, open-circuit voltage), EIS measurements were collected with an AC amplitude of $5 \mathrm{mV}$ over a frequency range of 0.01 to $10^{5} \mathrm{~Hz}$ using a $\mathrm{CHI} 760 \mathrm{E}$ electrochemical workstation. The $\mathrm{Na} \| \mathrm{Na}$ symmetric cells were prepared with asdeposited $\mathrm{Na}-\mathrm{Cu}$ foil as the working electrode, $\mathrm{Na}$ disc as the counter/reference electrode, and the coated side of functional separators toward the working electrode. The symmetric cells were applied to evaluate the long-time cycling stability of Na metal anodes with functional separators. The Na || NVP@C full cells were assembled with NVP@C based cathode (NVP@C mass loading of $\sim 1.0 \mathrm{mg} \mathrm{cm}^{-2}$ ), as-deposited $\mathrm{Na}$ anode $\left(10 \mathrm{mAh} \mathrm{cm}^{-2}\right)$ and functional separators combined with glass fiber $(\sim 675 \mu \mathrm{m})$. Finally, Cu || NVP@C cells consisting of NVP@C based cathode (NVP@C mass loading of $\sim 2.0 \mathrm{mg} \mathrm{cm}^{-2}$ ), Cu foil and functional separators were fabricated. Specifically, NVP@C was prepared by a sol-gel method ${ }^{63,79}$. $0.02 \mathrm{~mol}$ ammonium metavanadate was dissolved in $40 \mathrm{~mL}$ of deionized water under stirring at $80^{\circ} \mathrm{C}$ for $1 \mathrm{~h}$. Then, $0.03 \mathrm{~mol}$ ammonium dihydrogen phosphate and 0.01 mol sodium citrate dehydrate were added with stirring for $2 \mathrm{~h}$. When increasing the temperature to $120^{\circ} \mathrm{C}$, the solution gradually became gel. After drying and grinding, the precursor was annealed at $350{ }^{\circ} \mathrm{C}$ for $4 \mathrm{~h}$ and then $800{ }^{\circ} \mathrm{C}$ for $8 \mathrm{~h}$ in argon atmosphere to achieve target NVP@C powder. Furthermore, the NVP@C based cathode was prepared through mixing NVP@C ( 2.7 wt \% of carbon coating verified by carbon/sulfur elemental analyzer $)^{41,80-83}$, acetylene black and PVDF at a weight ratio of 80:10:10 in NMP $(\sim 0.3 \mathrm{~mL})$ and then pasting on a carbon-coated Al current collector $(\sim 18 \mu \mathrm{m})$. The electrochemical performance of Na || NVP@C full cells and Cu || NVP@C cells were measured between 2.5 and $3.8 \mathrm{~V}$ at varying C-rate. For the galvanostatic intermittent titration (GITT) measurement, the Na || NVP@C cell was first charged/discharged at $0.5 \mathrm{C}$ for five activation cycles. Then, the cell was charged and discharged at $0.5 \mathrm{C}$ for $6 \mathrm{~min}$, and relaxed for $60 \mathrm{~min}$ to reach the equilibrium state.

Computational simulation. DFT calculation and FVM simulation were conducted to study sodiophilic nature and Na-ion transportation behaviors of s-2D mPG heterostructures. In the frame work of DFT, all the calculations were performed with $\mathrm{Dmol}^{3}$ code $^{13,14,49}$. The generalized gradient approximation (GGA) combined with the Perdew-Burke-Enzerhof functional was employed to describe the exchange and correlation potential. The structural relaxations of polydopamine, graphene, $\mathrm{PP}$, and $\mathrm{Cu}$ (111) models were carried out firstly, followed with the $\mathrm{Na}$ adsorption simulation step. All the electrons were considered when tackling the electron-ion interactions for atoms in the whole system. For the convergence criteria, the SCF tolerance used was $1.0 \times 10^{-5} \mathrm{Ha} \cdot$ atom $^{-1}$, and the maximum force and displacement were set as $2.0 \times 10^{-5} \mathrm{Ha} \cdot \AA^{-1}$ and $5.0 \times 10^{-3} \AA$, respectively. The binding energies of $\mathrm{Na}$ atom with different substrate models $(\mathrm{C}=\mathrm{O},-\mathrm{OH},-\mathrm{NH}-$ groups of polydopamine, graphene, $\mathrm{PP}$, and $\mathrm{Cu}$ (111) surface) were defined as the energy difference between the substrate model with $\mathrm{Na}$ atom $\left(E_{\mathrm{tot}}\right)$ and the summation of $\mathrm{Na}$ atom $\left(E_{1}\right)$ and substrate system $\left(E_{2}\right): E_{\mathrm{ads}}=E_{1}+E_{2}-E_{\text {tot }}$.

For FVM simulation, OpenFOAM software was used to investigate the effect of mesopore size on $\mathrm{Na}$-ion distribution ${ }^{84}$. Two-dimensional simulation was conducted to study $\mathrm{Na}$-ion concentration distribution through the different $\mathrm{mPG}$ layers. Migration of $\mathrm{Na}$ ions driven by electric field and diffusion flow was taken into account in the simulation, and the governing equation of $\mathrm{Na}$-ion movement was shown below ${ }^{85}$ :

$$
\begin{gathered}
\frac{\partial c}{\partial t}=-\nabla \cdot \overrightarrow{\mathbf{N}} \\
\overrightarrow{\mathbf{N}}=-D \nabla c+\mu c \overrightarrow{\mathbf{E}} \\
\overrightarrow{\mathbf{E}}=-\nabla \varphi
\end{gathered}
$$

where $\varphi$ is potential difference, $\overrightarrow{\mathbf{E}}$ is electric filed, $c$ is Na-ion distribution, $\overrightarrow{\mathbf{N}}$ is flux of $\mathrm{Na}$ ions, $D$ is diffusion coefficient, $\mu$ is ionic mobility. In the simulation, the effect of pore size on Na-ion distribution are compared. According to the SEM, TEM and AFM results, three different physical models with varying pore sizes were constructed. Figure $3 \mathrm{~d}$ in the mansucript shows an example of the two-dimensional physical model. In the models, twenty crisscross layers based on the SEM result were constructed to simulate movement of $\mathrm{Na}$ ions. In each layer, six or five holes were constructed, and symmetry conditions were set to two sides to show the axial distribution of $\mathrm{Na}$ ions. Between the nearby layers was layer spacing, the $D$ and $\mu$ were regarded as same as $\mathrm{mPG}$ layers, and the simulated number were set to $3.0 \times 10^{-10} \mathrm{~m}^{2} \mathrm{~s}^{-1}$ and $3.0 \times 10^{-12} \mathrm{~m}^{2} \mathrm{~s}^{-1} \mathrm{~V}^{-1}$. In order to simulate the homogeneous distribution property of $\mathrm{mPG}$ layer, similar cosine function distribution of $\mathrm{Na}$ ions as shown in Fig. $3 \mathrm{e}$ in the manuscript was set in the entrance of different physical models. The electric field was set uniform in the whole simulation regime, and the value was set to $0.02 \mathrm{~V} \mathrm{~m}^{-1}$ according to experimental result. The Na-ion concentration of bottom boundary (i.e., outlet) was set to 0 . The inner boundaries induced by holes were set to zero gradient. Notably, two different simulations based on the varying entrance conditions were conducted. In one simulation, the entrance distribution of $\mathrm{Na}$ ions possessed same amplitude and period. In another simulation, the amplitude of entrance distribution of $\mathrm{Na}$ ions was adjusted to ensure same fluctuation.

\section{Data availability}

The experiment data that support the findings of this study are available from the corresponding authors upon reasonable requests.

Received: 9 September 2020; Accepted: 15 September 2021; Published online: 01 October 2021 


\section{References}

1. Goodenough, J. B. \& Park, K. S. The Li-ion rechargeable battery: a perspective. J. Am. Chem. Soc. 135, 1167-1176 (2013).

2. Cheng, X. B., Zhang, R., Zhao, C. Z. \& Zhang, Q. Toward safe lithium metal anode in rechargeable batteries: a review. Chem. Rev. 117, 10403-10473 (2017).

3. Bruce, P. G., Freunberger, S. A., Hardwick, L. J. \& Tarascon J.-M. Li-O ${ }_{2}$ and Li-S batteries with high energy storage. Nat. Mater. 11, 19-29 (2012).

4. Ma, L. et al. Dendrite-free lithium metal and sodium metal batteries. Energy Storage Mater. 27, 522-554 (2020).

5. Wang, Y. et al. Developments and perspectives on emerging high-energydensity sodium-metal batteries. Chem 5, 2547-2570 (2019).

6. Sun, B. et al. Design strategies to enable the efficient use of sodium metal anodes in high-energy batteries. Adv. Mater. 32, 1903891 (2020).

7. Lee, B., Paek, E., Mitlin, D. \& Lee, S. W. Sodium metal anodes: emerging solutions to dendrite growth. Chem. Rev. 119, 5416-5460 (2019).

8. Fan, L. \& Li, X. Recent advances in effective protection of sodium metal anode. Nano Energy 53, 630-642 (2018).

9. Vaalma, C., Buchholz, D., Weil, M. \& Passerini, S. A cost and resource analysis of sodium-ion batteries. Nat. Rev. Mater. 3, 18013 (2018).

10. Wei, S. et al. A stable room-temperature sodium-sulfur battery. Nat. Commun. 7, 11722 (2016).

11. Hartmann, P. et al. A rechargeable room-temperature sodium superoxide $\left(\mathrm{NaO}_{2}\right)$ battery. Nat. Mater. 12, 228-232 (2013).

12. Xu, X. et al. Quasi-solid-state dual-ion sodium metal batteries for low-cost energy storage. Chem 6, 902-918 (2020).

13. Wang, H., Matios, E., Luo, J. \& Li, W. Combining theories and experiments to understand the sodium nucleation behavior towards safe sodium metal batteries. Chem. Soc. Rev. 49, 3783-3805 (2020).

14. Ye, L. et al. A sodiophilic interphase-mediated, dendrite-free anode with ultrahigh specific capacity for sodium-metal batteries. Angew. Chem. Int. Ed. 58, 17054-17060 (2019).

15. $\mathrm{Hu}, \mathrm{X}$. et al. Quasi-solid state rechargeable $\mathrm{Na}-\mathrm{CO}_{2}$ batteries with reduced graphene oxide $\mathrm{Na}$ anodes. Sci. Adv. 3, e1602396 (2017).

16. Lee, J. et al. Ultraconcentrated sodium bis(fluorosulfonyl)imide-based electrolytes for high-performance sodium metal batteries. ACS Appl. Mater. Interfaces 9, 3723-3732 (2017).

17. Lee, Y. et al. Fluoroethylene carbonate-based electrolyte with $1 \mathrm{M}$ sodium bis(fluorosulfonyl)imide enables high-performance sodium metal electrodes. ACS Appl. Mater. Interfaces 10, 15270-15280 (2018).

18. Shim, J. et al. $2 \mathrm{D}$ boron nitride nanoflakes as a multifunctional additive in gel polymer electrolytes for safe, long cycle life and high rate lithium metal batteries. Energy Environ. Sci. 10, 1911-1916 (2017).

19. Zhou, W., Li, Y., Xin, S. \& Goodenough, J. B. Rechargeable sodium all-solidstate battery. ACS Cent. Sci. 3, 52-57 (2017).

20. Luo, W. et al. Ultrathin surface coating enables the stable sodium metal anode. Adv. Energy Mater. 7, 1601526 (2017).

21. Zhu, M. et al. Dendrite-free sodium metal anodes enabled by a sodium benzenedithiolate-rich protection layer. Angew. Chem. Int. Ed. 59, 6596-6600 (2020).

22. Wang, H., Wang, C., Matios, E. \& Li, W. Critical role of ultrathin graphene films with tunable thickness in enabling highly stable sodium metal anodes. Nano Lett. 17, 6808-6815 (2017).

23. Liu, S. et al. Porous $\mathrm{Al}$ current collector for dendrite-free $\mathrm{Na}$ metal anodes. Nano Lett. 17, 5862-5868 (2017).

24. Wang, A. et al. Processable and moldable sodium-metal anodes. Angew. Chem. Int. Ed. 56, 11921-11926 (2017).

25. Foroozan, T. et al. Synergistic effect of graphene oxide for impeding the dendritic plating of Li. Adv. Funct. Mater. 28, 1705917 (2018).

26. Zhang, C. et al. 2D materials for lithium/sodium metal anodes. Adv. Energy Mater. 8, 1802833 (2018).

27. Tu, N. D. K. et al. Co-solvent induced piezoelectric $\gamma$-phase nylon11 separator for sodium metal battery. Nano Energy 70, 104501 (2020).

28. Li, C. et al. Two-dimensional molecular brush-functionalized porous bilayer composite separators toward ultrastable high-current density lithium metal anodes. Nat. Commun. 10, 1363 (2019).

29. Li, N. et al. Normalized lithium growth from the nucleation stage for dendritefree lithium metal anodes. Angew. Chem. Int. Ed. 58, 18246-18251 (2019).

30. Kim, P. J. \& Pol, V. G. High performance lithium metal batteries enabled by surface tailoring of polypropylene separator with a polydopamine/graphene layer. Adv. Energy Mater. 8, 1802665 (2018).

31. Ryou, M.-H. et al. Excellent cycle life of lithium-metal anodes in lithium-ion batteries with mussel-inspired polydopamine-coated separators. Adv. Energy Mater. 2, 645-650 (2012).

32. Ryou, M. H., Lee, Y. M., Park, J. K. \& Choi, J. W. Mussel-inspired polydopamine-treated polyethylene separators for high-power Li-ion batteries. Adv. Mater. 23, 3066-3070 (2011).
33. Shi, H. D. et al. A two-dimensional mesoporous polypyrrole-graphene oxide heterostructure as a dual-functional ion redistributor for dendrite-free lithium metal anodes. Angew. Chem. Int. Ed. 59, 12147-12153 (2020).

34. Sun, T. et al. A biodegradable polydopamine-derived electrode material for high-capacity and long-life lithium-ion and sodium-ion batteries. Angew. Chem. Int. Ed. 55, 10662-10666 (2016).

35. Yue, X., Liu, H. \& Liu, P. Polymer grafted on carbon nanotubes as a flexible cathode for aqueous zinc ion batteries. Chem. Commun. 55, 1647-1650 (2019).

36. Liu, T. et al. Self-polymerized dopamine as an organic cathode for Li- and $\mathrm{Na}$ ion batteries. Energy Environ. Sci. 10, 205-215 (2017).

37. Liu, T. et al. In situ polymerization of dopamine on graphene framework for charge storage applications. Small 14, 1801236 (2018).

38. Li, W., Liu, J. \& Zhao, D. Mesoporous materials for energy conversion and storage devices. Nat. Rev. Mater. 1, 16023 (2016).

39. Liu, W., Lin, D., Pei, A. \& Cui, Y. Stabilizing lithium metal anodes by uniform Li-ion flux distribution in nanochannel confinement. J. Am. Chem. Soc. 138 15443-15450 (2016).

40. Bredar, A. R. C., Chown, A. L., Burton, A. R. \& Farnum, B. H. Electrochemical impedance spectroscopy of metal oxide electrodes for energy applications. ACS Appl. Energy Mater. 3, 66-98 (2020).

41. Zhou, Y. et al. A high-temperature Na-ion battery: boosting the rate capability and cycle life by structure engineering. Small 16, e1906669 (2020).

42. Li, S. et al. Developing high-performance lithium metal anode in liquid electrolytes: challenges and progress. Adv. Mater. 30, e1706375 (2018).

43. Liang, J. et al. A nano-shield design for separators to resist dendrite formation in lithium-metal batteries. Angew. Chem. Int. Ed. 59, 6561-6566 (2020).

44. Chu, C. et al. Uniform nucleation of sodium in 3D carbon nanotube framework via oxygen doping for long-life and efficient $\mathrm{Na}$ metal anodes. Energy Storage Mater. 23, 137-143 (2019).

45. Wang, S. et al. Stable sodium metal batteries via manipulation of electrolyte solvation structure. Small Methods 4, 1900856 (2020).

46. Shi, $H$. et al. 3D flexible, conductive, and recyclable $\mathrm{Ti}_{3} \mathrm{C}_{2} \mathrm{~T}_{\mathrm{x}}$ MXene-melamine foam for high-areal-capacity and long-lifetime alkali-metal anode. ACS Nano 14, 8678-8688 (2020).

47. Hou, Z. et al. Poly(vinylidene difluoride) coating on $\mathrm{Cu}$ current collector for high-performance Na metal anode. Energy Storage Mater. 24, 588-593 (2020).

48. Bao, C. et al. Sodiophilic decoration of a three-dimensional conductive scaffold toward a stable Na metal anode. ACS Sustain. Chem. Eng. 8, 5452-5463 (2020).

49. Sun, B. et al. Dendrite-free sodium-metal anodes for high-energy sodiummetal batteries. Adv. Mater. 30, 1801334 (2018)

50. Guo, M. et al. Three dimensional frameworks of super ionic conductor for thermodynamically and dynamically favorable sodium metal anode. Nano Energy 70, 104479 (2020).

51. Wang, G. et al. Core-shell C@Sb nanoparticles as a nucleation layer for highperformance sodium metal anodes. Nano Lett. 20, 4464-4471 (2020).

52. $\mathrm{Lu}, \mathrm{X}$. et al. Enabling high-performance sodium metal anodes via a sodiophilic structure constructed by hierarchical $\mathrm{Sb}_{2} \mathrm{MoO}_{6}$ microspheres. Nano Energy 69, 104446 (2020)

53. Luo, J. et al. Pillared MXene with ultralarge interlayer spacing as a stable matrix for high performance sodium metal anodes. Adv. Funct. Mater. 29, 1805946 (2019).

54. Wang, C., Wang, H., Matios, E., Hu, X. \& Li, W. A chemically engineered porous copper matrix with cylindrical core-shell skeleton as a stable host for metallic sodium anodes. Adv. Funct. Mater. 28, 1802282 (2018).

55. Luo, W. et al. Encapsulation of metallic $\mathrm{Na}$ in an electrically conductive host with porous channels as a highly stable Na metal anode. Nano Lett. 17, 3792-3797 (2017).

56. Zhang, Q. et al. A thermodynamically stable quasi-liquid interface for dendrite-free sodium metal anodes. J. Mater. Chem. A 8, 6822-6827 (2020).

57. $\mathrm{Wu}, \mathrm{F}$. et al. Reduced graphene oxide aerogel as stable host for dendrite-free sodium metal anode. Energy Storage Mater. 22, 376-383 (2019).

58. Chi, S.-S., Qi, X.-G., Hu, Y.-S. \& Fan, L.-Z. 3D flexible carbon felt host for highly stable sodium metal anodes. Adv. Energy Mater. 8, 1702764 (2018).

59. Zheng, X. et al. Embedding a percolated dual-conductive skeleton with high sodiophilicity toward stable sodium metal anodes. Nano Energy 69, 104387 (2020).

60. Li, G. et al. Stable metal battery anodes enabled by polyethylenimine sponge hosts by way of electrokinetic effects. Nat. Energy 3, 1076-1083 (2018).

61. Huang, C. J. et al. Decoupling the origins of irreversible coulombic efficiency in anode-free lithium metal batteries. Nat. Commun. 12, 1452 (2021).

62. Zhao, Y., Adair, K. R. \& Sun, X. Recent developments and insights into the understanding of $\mathrm{Na}$ metal anodes for $\mathrm{Na}$-metal batteries. Energy Environ. Sci. 11, 2673-2695 (2018).

63. Zhang, $\mathrm{X}$. et al. $\mathrm{Na}_{3} \mathrm{~V}_{2}\left(\mathrm{PO}_{4}\right)_{3}$ : An advanced cathode for sodium-ion batteries. Nanoscale 11, 2556-2576 (2019). 
64. Guo, D. et al. Achieving high mass loading of $\mathrm{Na}_{3} \mathrm{~V}_{2}\left(\mathrm{PO}_{4}\right)_{3} @$ carbon on carbon cloth by constructing three-dimensional network between carbon fibers for ultralong cycle-life and ultrahigh rate sodium-ion batteries. Nano Energy 45, 136-147 (2018).

65. Chen, S. et al. Challenges and perspectives for NASICON-type electrode materials for advanced sodium-ion batteries. Adv. Mater. 29, 1700431 (2017).

66. Jian, Z. et al. Atomic structure and kinetics of NASICON $\mathrm{Na}_{\mathrm{x}} \mathrm{V}_{2}\left(\mathrm{PO}_{4}\right)_{3}$ cathode for sodium-ion batteries. Adv. Funct. Mater. 24, 4265-4272 (2014)

67. Zhang, W. et al. Full activation of $\mathrm{Mn}^{4+} / \mathrm{Mn}^{3+}$ redox in $\mathrm{Na}_{4} \mathrm{MnCr}\left(\mathrm{PO}_{4}\right)_{3}$ as a high-voltage and high-rate cathode material for sodium-ion batteries. Small 16, e2001524 (2020).

68. Rui, X. et al. A low-temperature sodium-ion full battery: superb kinetics and cycling stability. Adv. Funct. Mater. 31, 2009458 (2020).

69. Zhang, J. et al. A novel NASICON-type $\mathrm{Na}_{4} \mathrm{MnCr}\left(\mathrm{PO}_{4}\right)_{3}$ demonstrating the energy density record of phosphate cathodes for sodium-ion batteries. $A d v$. Mater. 32, e1906348 (2020).

70. Ponrouch, A. et al. Non-aqueous electrolytes for sodium-ion batteries. J. Mater. Chem. A 3, 22-42 (2015).

71. Sun, Y. et al. Development and challenge of advanced nonaqueous sodium ion batteries. EnergyChem 2, 100031 (2020).

72. Sun, Y., Shi, P., Xiang, H., Liang, X. \& Yu, Y. High-safety nonaqueous electrolytes and interphases for sodium-ion batteries. Small 15, e1805479 (2019).

73. Ponrouch, A. et al. Towards high energy density sodium ion batteries through electrolyte optimization. Energy Environ. Sci. 6, 2361 (2013).

74. Ponrouch, A., Marchante, E., Courty, M., Tarascon, J.-M. \& Palacín, M. R. In search of an optimized electrolyte for Na-ion batteries. Energy Environ. Sci. 5, 8572 (2012).

75. Wu, J. et al. Sodiophilically graded gold coating on carbon skeletons for highly stable sodium metal anodes. Small 16, e2003815 (2020).

76. Shi, H. et al. Conducting and lithiophilic MXene/graphene framework for high-capacity, dendrite-free lithium-metal anodes. ACS Nano 13, 14308-14318 (2019).

77. Dreyer, D. R., Park, S., Bielawski, C. W. \& Ruoff, R. S. The chemistry of graphene oxide. Chem. Soc. Rev. 39, 228-240 (2010).

78. Zhu, Y. et al. Graphene and graphene oxide: synthesis, properties, and applications. Adv. Mater. 22, 3906-3924 (2010).

79. Yao, Y., Jiang, Y., Yang, H., Sun, X. \& Yu, Y. $\mathrm{Na}_{3} \mathrm{~V}_{2}\left(\mathrm{PO}_{4}\right)_{3}$ coated by N-doped carbon from ionic liquid as cathode materials for high rate and long-life $\mathrm{Na}$ ion batteries. Nanoscale 9, 10880-10885 (2017).

80. Liu, T. et al. Sustainability-inspired cell design for a fully recyclable sodium ion battery. Nat. Commun. 10, 1965 (2019).

81. Yao, Y. et al. Toward high energy density all solid-state sodium batteries with excellent flexibility. Adv. Energy Mater. 10, 1903698 (2020)

82. $\mathrm{Pi}$, Y. et al. Methanol-derived high-performance $\mathrm{Na}_{3} \mathrm{~V}_{2}\left(\mathrm{PO}_{4}\right)_{3} / \mathrm{C}$ : from kilogram-scale synthesis to pouch cell safety detection. Nanoscale 12, 21165-21171 (2020).

83. Chen, M. et al. Development and investigation of a NASICON-type highvoltage cathode material for high-power sodium-ion batteries. Angew. Chem. Int. Ed. 59, 2449-2456 (2020).

84. Weller, H. G., Tabor, G., Jasak, H. \& Fureby, C. A tensorial approach to computational continuum mechanics using object-oriented techniques. Comput. Phy. 12, 620-631 (1998).

85. Zhao, C. Z. et al. An ion redistributor for dendrite-free lithium metal anodes. Sci. Adv. 4, eaat3446 (2018).

\section{Acknowledgements}

We thank Prof. Qiang Fu and Dr. Chao Wang at Dalian Institute of Chemical Physics, Chinese Academy of Sciences for AFM supports. We also acknowledge the financial support from the National Key R\&D Program of China (Grant 2016YFA0200200), National Natural Science Foundation of China (Grants 51872283, 22125903, 22075279, U1910210, 22005297, 22005298), LiaoNing Revitalization Talents Program (Grant XLYC1807153), Dalian Innovation Support Plan for High Level Talents (2019RT09), DICP (DICP ZZBS201708, DICP ZZBS201802, and DICP I202032), Dalian National Laboratory For Clean Energy (DNL), CAS, DNL Cooperation Fund, CAS (DNL201912 and DNL201915, DNL202016, DNL202019), the Joint Fund of the Yulin University and the Dalian National Laboratory for Clean Energy (YLU-DNL Fund 2021002, 2021009), and the Fundamental Research Funds for the Central Universities (WK2060140026).

\section{Author contributions}

Z.-S.W., M.Y., and Y.Y. proposed and supervised the overall project. J.Q. and H.S. prepared the samples and performed the electrochemical measurements. K.H. did the FVM simulations. P.L. did the DFT simulations. P.W., F.X., and B.Y. performed the SEM and TEM measurements of materials. J.Q., H.S., K.H., M.Y., Y.Y., and Z.-S.W. analyzed the data and wrote the paper. All authors discussed the results and commented on the manuscript. All authors have given approval to the final version of the manuscript.

\section{Competing interests}

The authors declare no competing interests.

\section{Additional information}

Supplementary information The online version contains supplementary material available at https://doi.org/10.1038/s41467-021-26032-1.

Correspondence and requests for materials should be addressed to Mao Ye, Yan Yu or Zhong-Shuai $\mathrm{Wu}$.

Peer review information Nature Communications thanks Tom Nilges, Palani Balaya and Haegyeom Kim for their contribution to the peer review of this work.

Reprints and permission information is available at http://www.nature.com/reprints

Publisher's note Springer Nature remains neutral with regard to jurisdictional claims in published maps and institutional affiliations.

(c) (i) Open Access This article is licensed under a Creative Commons C. Attribution 4.0 International License, which permits use, sharing, adaptation, distribution and reproduction in any medium or format, as long as you give appropriate credit to the original author(s) and the source, provide a link to the Creative Commons license, and indicate if changes were made. The images or other third party material in this article are included in the article's Creative Commons license, unless indicated otherwise in a credit line to the material. If material is not included in the article's Creative Commons license and your intended use is not permitted by statutory regulation or exceeds the permitted use, you will need to obtain permission directly from the copyright holder. To view a copy of this license, visit http://creativecommons.org/ licenses/by/4.0/.

(C) The Author(s) 2021 